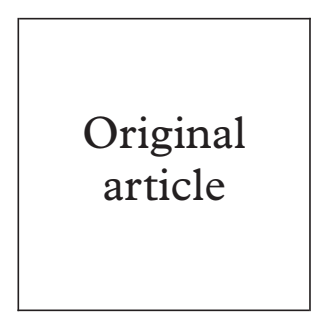

\title{
Comparison of risk factors for four sexually transmitted infections: results from a study of attenders at three genitourinary medicine clinics in England
}

\author{
G Hughes, M Catchpole, P A Rogers, A R Brady, G Kinghorn, D Mercey, N Thin
}

Objective: To compare the risk factors for four common sexually transmitted infections (STIs) in attenders at three large urban genitourinary medicine (GUM) clinics in England.

Methods: Clinical, demographic, and behavioural data on attenders at two clinics in London and one in Sheffield were collected. Risk factors associated with first episodes of genital warts and genital herpes simplex virus (HSV), and uncomplicated gonorrhoea and chlamydia were investigated using the presence of each of these STIs as the outcome variable in separate multiple logistic regression analyses.

Results: Using data on the first attendance of the 18238 patients attending the clinics in 1996, the risk of a gonorrhoea or chlamydia diagnosis was strongly associated with teenagers compared with those aged over 34, with black Caribbeans and black Africans compared with whites, and increased with the number of sexual partners. The risk of genital warts or HSV diagnosis was lowest in black Caribbeans and black Africans compared with whites and was not associated with the number of sexual partners. While genital warts were associated with younger age, odds ratios were much lower compared with those for the bacterial infections. Genital HSV diagnoses were not associated with age.

Conclusions: This study of GUM clinic attenders suggests a reduction in the incidence of bacterial STIs may be achievable through targeted sexual health promotion focusing particularly on black ethnic minorities, teenagers, and those with multiple sexual partnerships. Viral STIs were less clearly associated with population subgroups and a broader population based approach to sexual health promotion may be more effective in controlling these infections.

(Sex Transm Inf 2000;76:262-267)

Keywords: risk factors; sexually transmitted infections; genitourinary medicine clinics; England

PHLS Communicable Disease Surveillance Centre, 61 Colindale Avenue, London NW9 5EQ

G Hughes

M Catchpole

PHLS Statistics Unit, 61 Colindale Avenue, London NW9 5EQ

P A Rogers

Department of Medical Statistics and Evaluation, Imperial College School of Medicine, London A R Brady

Royal Hallamshire Hospital, Sheffield G Kinghorn

Mortimer Market Centre, London D Mercey

Guy's and St Thomas's Hospital Trust, London

$\mathrm{N}$ Thin

Correspondence to: Dr Gwenda Hughes ghughes@phls.nhs.uk

Accepted for publication 20 April 2000

\section{Introduction}

Sexually transmitted infections (STIs) excluding HIV are a major cause of infectious disease morbidity in countries with established market economies. ${ }^{1}$ The late 1980 s and early 1990 s witnessed a decline in, or at least plateauing of, numbers of diagnoses of many STIs in England and Wales. ${ }^{2-5}$ Since the mid-1990s, there has been a resurgence of diagnoses of STIs in genitourinary medicine (GUM) clinics, particularly of gonorrhoea, genital chlamydial infection, and genital warts. ${ }^{6}{ }^{7}$ In response to this, renewed efforts towards the control and prevention of STIs, particularly in teenagers, have been recommended. ${ }^{68}$

STI prevention campaigns need to be targeted and relevant if they are to be effective. ${ }^{910}$ Since STI transmission is uniquely linked to human behaviour, the identification of important risk groups and risk behaviours associated with STI transmission is essential for their control. However, the major source of routine surveillance data on STIs in England and Wales, the KC60 statistical return from GUM clinics, includes limited information on risk factors, has no information on sexual behaviour, and does not allow repeat attendances or concurrent infections to be identified. ${ }^{11}$
To address the need for enhanced STI surveillance data, a pilot study was set up in three GUM clinics in England which provided clinical, demographic, and behavioural information on individual patient attendances. We have previously demonstrated how GUM clinic attenders included in this study differ from the general population in terms of their sexual behaviour, and identified which attenders were at particular risk for acquiring any acute STI. ${ }^{12}$ In this paper, we develop the latter investigation and show how risk factors associated with specific STIs can vary considerably, by comparing the risk factor profiles of four of the commonest STIs: genital warts, genital herpes simplex virus (HSV), gonorrhoea, and genital chlamydial infection.

\section{Methods}

Three GUM clinics participated in the sentinel surveillance scheme: St Thomas's Hospital (London) and the Mortimer Market Centre (MMC) (London), and the Royal Hallamshire Hospital (Sheffield). Data were collected between the 1 April 1994 and the 30 September 1997. Details of the core dataset have been published previously. ${ }^{12}$ Diagnosis (KC60 code), demographic characteristics, and risk behaviours were collected for each patient attendance and sent to the Communicable 
Table 1 Characteristics of patients attending three GUM clinics in England, April 1994 to September 1997

\begin{tabular}{|c|c|c|c|}
\hline & $\begin{array}{l}\text { Royal Hallamshire, } \\
\text { Sheffield }(\%)\end{array}$ & $\begin{array}{l}\text { St Thomas's, London } \\
(\%)\end{array}$ & $\begin{array}{l}\text { Mortimer Market } \\
\text { Centre }(M M C) \text {, } \\
\text { London }^{3}(\%)\end{array}$ \\
\hline Total attenders & 20334 & 15155 & 8471 \\
\hline \multicolumn{4}{|l|}{ Sex } \\
\hline Males & $9992(49)$ & $7969(53)$ & $4194(50)$ \\
\hline Females & $10314(51)$ & $7186(47)$ & $4273(50)$ \\
\hline Not recorded & $28(<1)$ & - & $4(<1)$ \\
\hline \multicolumn{4}{|l|}{ Age group } \\
\hline $13-15$ & $189(1)$ & $64(<1)$ & $8(<1)$ \\
\hline $16-19$ & $2319(11)$ & $977(6)$ & $404(5)$ \\
\hline $20-24$ & $5672(28)$ & $3199(21)$ & $1895(22)$ \\
\hline $25-34$ & $7809(38)$ & 7425 (49) & $4189(49)$ \\
\hline $35+$ & $4254(21)$ & $3485(23)$ & $1973(23)$ \\
\hline Not recorded & $91(<1)$ & $5(<1)$ & $2(<1)$ \\
\hline \multicolumn{4}{|c|}{ Male sexual orientation } \\
\hline Heterosexual & $9181(92)$ & $6744(85)$ & $2221(53)$ \\
\hline Homo/bisexual & $800(8)$ & $1174(15)$ & $1759(42)$ \\
\hline Not recorded & $11(<1)$ & $51(1)$ & $214(5)$ \\
\hline \multicolumn{4}{|c|}{ Female sexual orientation } \\
\hline Heterosexual & $10145(98)$ & $7057(98)$ & $3994(93)$ \\
\hline Homo/bisexual & $165(2)$ & $89(1)$ & $51(1)$ \\
\hline Not recorded & $4(<1)$ & $40(1)$ & $228(5)$ \\
\hline \multicolumn{4}{|l|}{ Ethnic group } \\
\hline White & $18014(89)$ & $8383(55)$ & $5031(59)$ \\
\hline Black Caribbean & $1038(5)$ & $4308(28)$ & 269 (3) \\
\hline Black African & $140(1)$ & $1611(11)$ & $252(3)$ \\
\hline Asian & $483(2)$ & $496(3)$ & $265(3)$ \\
\hline Other/mixed ${ }^{4}$ & $297(1)$ & $357(2)$ & $2654(31)$ \\
\hline Not recorded & $362(2)$ & - & - \\
\hline \multicolumn{4}{|l|}{ Presenting diagnosis } \\
\hline Genital warts ${ }^{5}$ & $1976(10)$ & $963(6)$ & $393(5)$ \\
\hline Genital HSV ${ }^{5}$ & $548(3)$ & $433(3)$ & $158(2)$ \\
\hline Gonorrhoea $^{6}$ & $389(2)$ & $559(4)$ & $177(2)$ \\
\hline Chlamydia $^{6}$ & $2175(11)$ & $752(5)$ & $419(5)$ \\
\hline \multicolumn{4}{|c|}{ Number of partners ${ }^{7}$ (heterosexuals) } \\
\hline $0-1$ & $10353(53)$ & $7299(53)$ & $2920(47)$ \\
\hline 2 & $5027(26)$ & $3541(26)$ & $1616(26)$ \\
\hline $3+$ & $3961(20)$ & $2802(20)$ & $1679(27)$ \\
\hline Not recorded & $13(<1)$ & $159(1)$ & - \\
\hline \multicolumn{4}{|l|}{ Previous STI } \\
\hline Yes & $5791(28)$ & $5807(38)$ & $3488(41)$ \\
\hline Not recorded & - & $3(<1)$ & $118(1)$ \\
\hline \multicolumn{4}{|l|}{ Ever injected drugs } \\
\hline Yes & $361(2)$ & $228(2)$ & $145(2)$ \\
\hline Not recorded & - & $2(<1)$ & $74(1)$ \\
\hline \multicolumn{4}{|c|}{ Commercial sex work (ever) } \\
\hline Yes & $543(3)$ & - & $185(2)$ \\
\hline Not recorded & - & $15155(100)$ & 229 (3) \\
\hline
\end{tabular}

1 Data for 1 April 1994 to 30 September 1997.

2 Data for 1 April 1994 to 31 December 1996.

3 Data for 1996 only.

4 Includes "black other."

5 First episode.

6 Uncomplicated infection.

7 Number of partners in past 12 months for Sheffield and St Thomas's clinics and in past 3 months for MMC (see methods for details).

Disease Surveillance Centre (CDSC) electronically. Personal identifiers were not included in the datasets submitted to CDSC, although each patient had a unique clinic number which allowed repeat attendances to be identified. Demographic and diagnostic information was taken from the patient records whereas behavioural information was recorded on specifically designed proformas completed by the attending doctor at each patient consultation. Ethnic group was self assigned whereas information on sexual behaviour was assigned by the doctor during the consultation. Gonorrhoea was diagnosed by microscopy and culture. Genital chlamydial infection was diagnosed by enzyme assay at the Royal Hallamshire and St Thomas's and by ligase chain reaction at MMC. The vast majority of patients were tested for these STIs as it is policy in each clinic to encourage all attenders to have a full STI screen, even those presenting for an HIV test. The local research ethics committees were informed of this enhanced surveillance.
All descriptive and statistical analyses used data on the first attendance of all patients who attended during the period 1994-7, apart from the STI risk factor models which used data from 1996. Statistical analyses were undertaken using statA. ${ }^{13}$ Differences in patient characteristics across clinics, between those presenting and not presenting with an acute STI, and in numbers of partners by ethnic group, were tested for statistical significance using $\chi^{2}$ tests.

Univariable and multivariable logistic regression analyses were used to investigate risk factors associated with specific STIs. The analyses only included data for the first attendance of each patient presenting in 1996, as this was the only year for which a complete set of data was available. The presence of first episode of genital warts, first episode of genital HSV, uncomplicated gonorrhoea, and uncomplicated chlamydia were each taken as the outcome variable in separate logistic regression analyses. Over $94 \%$ of patients diagnosed with any of these STIs had a single infection. The effect of multiple infections in the analyses was ignored. Risk factors which were significant at $\mathrm{p}<0.2$ in the univariable analyses were included in the multivariable models. Initially, multivariable models for each STI were run separately for each clinic, and for males and females. The odds ratios for each variable varied little between clinics, therefore data from all clinics were pooled and clinic included as a factor in the final models. The time period relating to previous sexual partners varied by clinic (previous 12 months for St Thomas's and the Royal Hallamshire, previous 3 months for MMC) but the initial within-clinic analyses demonstrated the same effect for each STI regardless of time period. Interactions between clinic and all other variables included in the models were investigated.

\section{Results}

The results of all analyses except the risk factor models are based on data collected from the Royal Hallamshire Hospital between 1 April 1994 and the 30 September 1997, from St Thomas's Hospital between 1 April 1994 and the 31 December 1996 and from MMC in 1996. In all, 43960 patients made 65589 attendances and were assigned 87618 diagnoses.

PATIENT CHARACTERISTICS AND STI DIAGNOSES Demographic and behavioural characteristics of patients attending the three clinics are presented in table 1 . There were significant differences in the distribution of attenders at the clinics by age $\left(\chi^{2}(8)=994, \mathrm{p}<0.001\right)$, ethnic group $\left(\chi^{2}(8)=15822, \mathrm{p}<0.001\right)$ and male sexual orientation $\left(\chi^{2}(2)=2676, \mathrm{p}<0.001\right)$. The proportion of attenders reporting a previous STI, and the proportion of attenders diagnosed with genital warts and genital chlamydial infection also varied significantly by clinic $\left(\chi^{2}(2)=620, \mathrm{p}<0.001 ; \chi^{2}(2)=270, \mathrm{p}<0.001 ;\right.$ $\chi^{2}(2)=512, \mathrm{p}<0.001$; previous STI, warts and chlamydia respectively). 
Table 2 Numbers of attenders diagnosed with first episode genital warts, first episode genital HSV, uncomplicated gonorrhoea, and uncomplicated chlamydia, showing concurrent infections, in attenders at three GUM clinics in England, April 1994 to September 1997

\begin{tabular}{|c|c|c|c|c|}
\hline Number of attenders (\%) & Warts & $H S V$ & Gonorrhoea & Chlamydia \\
\hline $3111(7.08)$ & + & - & - & - \\
\hline $2911(6.62)$ & - & - & - & + \\
\hline $1080(2.46)$ & - & + & - & - \\
\hline $861(1.96)$ & - & - & + & - \\
\hline $224(0.51)$ & - & - & + & + \\
\hline $174(0.40)$ & + & - & - & + \\
\hline $26(0.06)$ & - & + & - & + \\
\hline $20(0.05)$ & + & + & - & - \\
\hline $18(0.04)$ & + & - & + & - \\
\hline $11(0.03)$ & - & + & + & - \\
\hline $9(0.02)$ & + & - & + & + \\
\hline $2(0.00)$ & - & + & + & + \\
\hline $35513(80.78)$ & - & - & - & - \\
\hline $43960(100)$ & & & & \\
\hline
\end{tabular}

$+=$ present,$-=$ absent

Numbers of attenders presenting with first episode genital warts, first episode genital HSV, uncomplicated gonorrhoea and uncomplicated chlamydia, and with combinations of these infections, are shown in table 2 . Of the 31542 patients $(72 \%)$ who did not attend with any acute STI (definition of acute STI published previously ${ }^{12}$ ), $11 \%$ had anogenital candidosis, $27 \%$ had HIV antibody counselling with testing, $14 \%$ had another non-STI episode requiring treatment, and $40 \%$ had a non-STI episode and did not require treatment. Compared with those without an acute STI, patients with an acute STI were more likely to be male ( $62 \%$ compared with $46 \%$, $\left.\chi^{2}(1)=842, p<0.001\right)$, aged $16-19$ years $(12 \%$ compared with $\left.7 \%, \chi^{2}(4)=578, \mathrm{p}<0.001\right)$, black Caribbean (18\% compared with $11 \%$, $\left.\chi^{2}(4)=461, p<0.001\right)$, and to report three or more sexual partners (32\% compared with $\left.23 \%, \chi^{2}(2)=642, p<0.001\right)$.

Numbers of partners in the 12 month period before attendance were compared between ethnic groups for heterosexual males and females (data on attenders at MMC were unavailable for this period). There were significant differences in the numbers of partners reported by ethnic group for both males $\left(\chi^{2}(8)=225\right.$, p $<0.001)$ and females $\left(\chi^{2}(8)=314, \mathrm{p}<0.001\right)$. Apart from Asian men, most men reported two or more sexual partners in the previous 12 months. A greater proportion of black Caribbean men reported three or more sexual partners than men in any other ethnic group (36\% compared with $26 \%$ or less in the other ethnic groups). The majority of females in all ethnic groups reported one or no sexual partners in past 12 months. More white females reported two or more partners than females in any other ethnic group (41\% compared with $35 \%$ or less in the other ethnic groups). (A table of the raw data is available from the journal office.)

\section{RISK FACTOR ANALYSES}

All risk factor models used data on 18238 patients attending the clinics in 1996. In the univariable analyses "clinic," "age group," "sexual orientation," "ethnic group," "number of sexual partners," "previous STI," and "ever injected drugs" were found to be significant at $\mathrm{p}<0.2$ for one or more of the four STIs being investigated, and were included in the multivariable analyses. Independent risk factors for first episode of genital warts, first episode of genital HSV, uncomplicated gonorrhoea, and uncomplicated genital chlamydial infection are shown for males and females in tables 3 and 4, respectively.

\section{Genital warts}

Attendance with genital warts was strongly associated with white ethnicity; all other ethnic groups, except Asian, had significantly lower odds ratios. The risk of a warts diagnosis was also greatest in 16-19 year old males and females compared with other age groups, was greatest in heterosexual men compared with homosexual men, but was not associated with the number of sexual partners. Females

Table 3 Independent risk factors for four common sexually transmitted infections in attenders at three GUM clinics in England, 1996: males

\begin{tabular}{|c|c|c|c|c|c|c|c|c|c|c|c|c|}
\hline \multirow[b]{2}{*}{ Variable } & \multicolumn{3}{|l|}{ Warts } & \multicolumn{3}{|l|}{$H S V$} & \multicolumn{3}{|c|}{ Gonorrhoea } & \multicolumn{3}{|c|}{ Chlamydia } \\
\hline & $\begin{array}{l}\text { Odds } \\
\text { ratio }\end{array}$ & $95 \% C I$ & p Value & $\begin{array}{l}\text { Odds } \\
\text { ratio }\end{array}$ & $95 \% C I$ & $p$ Value & $\begin{array}{l}\text { Odds } \\
\text { ratio }\end{array}$ & $95 \% C I$ & $p$ Value & $\begin{array}{l}\text { Odds } \\
\text { ratio }\end{array}$ & $95 \% C I$ & $p$ Value \\
\hline \multicolumn{13}{|l|}{ Clinic } \\
\hline Sheffield & 1.00 & & & 1.00 & & & 1.00 & & & 1.00 & & \\
\hline St Thomas's & 0.93 & $0.75-1.14$ & & 1.34 & $0.91-1.99$ & & 1.87 & $1.37-2.55$ & & 0.38 & $0.30-0.49$ & \\
\hline MMC & 0.60 & $0.49-0.75$ & $<0.001$ & 1.37 & $0.94-2.01$ & 0.19 & 1.03 & $0.73-1.45$ & $<0.001$ & 0.78 & $0.63-0.97$ & $<0.001$ \\
\hline \multicolumn{13}{|l|}{ Age group } \\
\hline $13-15$ & 1.69 & $0.21-13.22$ & & - & - & & 8.97 & $1.77-45.42$ & & 3.54 & $0.73-17.28$ & \\
\hline $16-19$ & 2.59 & $1.79-3.75$ & & 1.38 & $0.60-3.17$ & & 3.94 & $2.48-6.24$ & & 3.86 & $2.63-5.66$ & \\
\hline $20-24$ & 2.45 & $1.92-3.13$ & & 1.87 & $1.17-2.97$ & & 1.93 & $1.36-2.73$ & & 2.91 & $2.18-3.89$ & \\
\hline $25-34$ & 1.61 & $1.29-2.01$ & & 1.79 & $1.21-2.65$ & & 1.69 & $1.27-2.25$ & & 2.23 & $1.71-2.90$ & \\
\hline $35+$ & 1.00 & & $<0.001$ & 1.00 & & 0.01 & 1.00 & & $<0.001$ & 1.00 & & $<0.001$ \\
\hline \multicolumn{13}{|l|}{ Sexual orientation } \\
\hline Heterosexual & 1.00 & & & 1.00 & & & 1.00 & & & 1.00 & & \\
\hline Homo/bisexual & 0.76 & $0.60-0.95$ & 0.01 & 0.79 & $0.52-1.19$ & 0.25 & 3.59 & $2.74-4.70$ & $<0.001$ & 0.18 & $0.13-0.26$ & $<0.001$ \\
\hline \multicolumn{13}{|l|}{ Ethnic group } \\
\hline White & 1.00 & & & 1.00 & & & 1.00 & & & 1.00 & & \\
\hline Black Caribbean & 0.34 & $0.24-0.49$ & & 0.90 & $0.55-1.47$ & & 4.32 & $3.19-5.85$ & & 2.16 & $1.66-2.80$ & \\
\hline Black African & 0.40 & $0.24-0.66$ & & 0.94 & $0.49-1.80$ & & 2.50 & $1.58-3.95$ & & 3.26 & $2.36-4.52$ & \\
\hline Asian & 0.83 & $0.53-1.31$ & & 0.92 & $0.40-2.11$ & & 2.03 & $1.12-3.67$ & & 1.49 & $0.93-2.37$ & \\
\hline Other/mixed & 0.56 & $0.40-0.79$ & $<0.001$ & 0.54 & $0.30-0.97$ & 0.30 & 1.20 & $0.85-1.68$ & $<0.001$ & 1.26 & $0.91-1.74$ & $<0.001$ \\
\hline \multicolumn{13}{|c|}{ Number of partners in past 12 months ${ }^{\star}$} \\
\hline $0-1$ & 1.00 & & & 1.00 & & & 1.00 & & & 1.00 & & \\
\hline 2 & 0.78 & $0.63-0.96$ & & 0.96 & $0.67-1.38$ & & 1.74 & $1.21-2.50$ & & 1.70 & $1.35-2.14$ & \\
\hline $3+$ & 0.90 & $0.75-1.09$ & 0.07 & 0.68 & $0.48-0.98$ & 0.08 & 3.03 & $2.22-4.14$ & $<0.001$ & 2.24 & $1.81-2.77$ & $<0.001$ \\
\hline Previous STI & 1.07 & $0.90-1.27$ & 0.46 & 0.99 & $0.72-1.34$ & 0.93 & 1.16 & $0.93-1.45$ & 0.19 & 0.85 & $0.70-1.02$ & 0.08 \\
\hline Ever injected drugs & 0.56 & $0.30-1.04$ & 0.05 & 1.40 & $0.61-3.21$ & 0.45 & 1.23 & $0.54-2.34$ & 0.75 & 0.81 & $0.45-1.48$ & 0.49 \\
\hline
\end{tabular}

^Number of partners in the past 3 months for MMC (see Methods for details). 
presenting with genital warts were less likely than all other female attenders to have had an STI previously.

\section{Genital HSV}

Odds ratios for an HSV diagnosis were lower for those of non-white ethnicity compared with whites, but were only significantly lower in the "other/mixed" (predominantly "black other") category and black Caribbean females. The risk of genital HSV was greatest in 20-24 year old men but did not vary significantly with age in females or with the number of sexual partners. Females presenting with genital HSV were less likely than all other female attenders to have previously had an STI.

\section{Gonorrhoea}

The risk of a gonorrhoea diagnosis was strongly associated with being a teenager (particularly for females) and being in the black Caribbean, black African, and "other/mixed" (females only) ethnic groups, compared with whites. Homosexual men were at greater risk than heterosexual men and the risk increased significantly with the number of sexual partners.

\section{Genital chlamydial infection}

The risk of a genital chlamydia diagnosis was greatest in teenagers compared with older attenders, in black Caribbeans and black Africans (males only) compared with whites, and in heterosexuals compared with homo/bisexuals. The risk also increased significantly with the number of sexual partners.

Interactions between clinic and other variables Most interactions with clinic occurred in the gonorrhoea risk factor model for males. Males reporting two partners were more likely to be diagnosed with gonorrhoea at MMC than those reporting two partners at the other two clinics. The risk of a gonorrhoea diagnosis was also greater in males of "other/mixed" ethnicity at MMC than at the other two clinics, and in males aged 20-34 years in St Thomas's compared with the other two clinics. The risk of a warts diagnosis was greater in those reporting a previous STI in the London clinics than in the Sheffield clinic.

\section{Discussion}

Patients attending GUM clinics exhibit higher risk sexual behaviour than the general population. ${ }^{12}$ Even within this high risk group, STI acquisition has been linked to higher rates of sexual partner change and young age. ${ }^{12}$ This analysis suggests that risk factors vary considerably with the type of STI diagnosed. In particular, risk factors associated with viral STIs were different from those associated with bacterial STIs.

The demographic characteristics of patients presenting with genital warts and genital HSV contrasted with those of patients diagnosed with gonorrhoea and chlamydia. Whereas white attenders were at much greater risk of diagnosis with a viral STI, particularly genital warts, black Caribbean and black African attenders were at greater risk of diagnosis with a bacterial STI. Associations between black ethnicity and infection with bacterial STIs have been shown before. ${ }^{14-16}$ However, such associations should be interpreted with care $^{17}$ as ethnicity probably serves as a marker for cultural influences on sexual behaviour-for example, black males report less frequent use of condoms than white males, ${ }^{18}$ differences in sexual mixing patterns, and inequalities in socioeconomic status and health seeking behaviour. ${ }^{19}$ Data on condom usage and socioeconomic status were not collected and their influence cannot be evaluated in this study. Among heterosexuals, black Caribbean males had higher numbers of partners than men in other ethnic groups, but black Caribbean

Table 4 Independent risk factors for four common sexually transmitted infections in attenders at three GUM clinics in England, 1996: females

\begin{tabular}{|c|c|c|c|c|c|c|c|c|c|c|c|c|}
\hline \multirow[b]{2}{*}{ Variable } & \multicolumn{3}{|l|}{ Warts } & \multicolumn{3}{|l|}{$H S V$} & \multicolumn{3}{|c|}{ Gonorrhoea } & \multicolumn{3}{|c|}{ Chlamydia } \\
\hline & $\begin{array}{l}\text { Odds } \\
\text { ratio }\end{array}$ & $95 \% C I$ & $p$ Value & $\begin{array}{l}\text { Odds } \\
\text { ratio }\end{array}$ & $95 \% C I$ & $p$ Value & $\begin{array}{l}\text { Odds } \\
\text { ratio }\end{array}$ & $95 \% C I$ & $p$ Value & $\begin{array}{l}\text { Odds } \\
\text { ratio }\end{array}$ & $95 \% C I$ & $p$ Value \\
\hline \multicolumn{13}{|l|}{ Clinic } \\
\hline Sheffield & 1.00 & & & 1.00 & & & 1.00 & & & 1.00 & & \\
\hline St Thomas's & 0.90 & $0.73-1.12$ & & 1.22 & $0.90-1.66$ & & 1.72 & $1.14-2.59$ & & 0.44 & $0.35-0.55$ & \\
\hline MMC & 0.61 & $0.50-0.74$ & $<0.001$ & 0.71 & $0.52-0.96$ & $<0.005$ & 0.33 & $0.19-0.58$ & $<0.001$ & 0.53 & $0.44-0.64$ & $<0.001$ \\
\hline \multicolumn{13}{|l|}{ Age group } \\
\hline $13-15$ & 2.20 & $0.91-5.33$ & & 1.11 & $0.26-4.73$ & & 18.98 & $5.99-60.09$ & & 30.73 & $15.48-61.00$ & \\
\hline $16-19$ & 3.07 & $2.24-4.22$ & & 1.30 & $0.83-2.05$ & & 14.75 & $6.69-32.55$ & & 15.28 & $9.65-24.19$ & \\
\hline $20-24$ & 2.27 & $1.70-3.03$ & & 1.27 & $0.87-1.86$ & & 4.47 & $2.01-9.92$ & & 8.15 & $5.19-12.78$ & \\
\hline $25-34$ & 1.41 & $1.05-1.88$ & & 1.13 & $0.79-1.63$ & & 1.95 & $0.87-4.40$ & & 4.69 & $2.99-7.36$ & \\
\hline $35+$ & 1.00 & & $<0.001$ & 1.00 & & 0.72 & 1.00 & & $<0.001$ & 1.00 & & $<0.001$ \\
\hline \multicolumn{13}{|l|}{ Sexual orientation } \\
\hline Heterosexual & 1.00 & & & 1.00 & & & 1.00 & & & 1.00 & & \\
\hline Homo/bisexual & 0.54 & $0.24-1.24$ & 0.11 & 0.44 & $0.11-1.80$ & 0.19 & 0.58 & $0.08-4.29$ & 0.56 & 0.08 & $0.01-0.55$ & $<0.001$ \\
\hline \multicolumn{13}{|l|}{ Ethnic group } \\
\hline White & 1.00 & & & 1.00 & & & 1.00 & & & 1.00 & & \\
\hline Black Caribbean & 0.30 & $0.21-0.45$ & & 0.59 & $0.38-0.91$ & & 3.13 & $2.06-4.76$ & & 2.08 & $1.62-2.68$ & \\
\hline Black African & 0.45 & $0.27-0.77$ & & 0.48 & $0.23-1.01$ & & 2.34 & $1.24-4.41$ & & 0.78 & $0.47-1.29$ & \\
\hline Asian & 0.38 & $0.19-0.74$ & & 0.82 & $0.40-1.69$ & & 1.59 & $0.62-4.04$ & & 1.26 & $0.81-1.98$ & \\
\hline Other/mixed & 0.70 & $0.51-0.96$ & $<0.001$ & 0.56 & $0.33-0.93$ & $<0.01$ & 3.23 & $1.82-5.74$ & $<0.001$ & 1.16 & $0.84-1.48$ & $<0.001$ \\
\hline \multicolumn{13}{|c|}{ Number of partners in past 12 months ${ }^{\star}$} \\
\hline $0-1$ & 1.00 & & & 1.00 & & & 1.00 & & & 1.00 & & \\
\hline 2 & 1.11 & $0.92-1.35$ & & 1.03 & $0.78-1.37$ & & 1.58 & $1.11-2.26$ & & 1.41 & $1.18-1.69$ & \\
\hline $3+$ & 1.26 & $1.02-1.54$ & 0.09 & 1.13 & $0.83-1.55$ & 0.75 & 1.82 & $1.22-2.71$ & $<0.005$ & 1.57 & $1.30-1.90$ & $<0.001$ \\
\hline Previous STI & 0.62 & $0.51-0.75$ & $<0.001$ & 0.66 & $0.50-0.86$ & $<0.005$ & 0.93 & $0.66-1.30$ & 0.18 & 0.89 & $0.76-1.06$ & 0.18 \\
\hline Ever injected drugs & 0.57 & $0.23-1.41$ & 0.19 & 0.59 & $0.14-2.41$ & 0.42 & & - & - & 0.84 & $0.40-1.80$ & 0.65 \\
\hline
\end{tabular}

${ }^{\star}$ Number of partners in the past 3 months for MMC (see Methods for details). 
females reported far fewer partners than white females.

Increased risk of viral STIs among white attenders compared with other ethnic groups is less well documented. A study of female attenders at another GUM clinic in London found an association between white ethnicity and a diagnosis of genital warts. ${ }^{16}$ Reasons for this relation are unclear. At GUM clinics patients are routinely tested for both symptomatic and asymptomatic bacterial STIs, but diagnosis of genital warts or genital HSV relies upon the presence of clinical indicators. In the case of HSV infection, those of lower socioeconomic status are more likely to have been exposed to oral HSV-1 infection as children, rendering them less susceptible to genital HSV-1 infection ${ }^{20}$ and possibly less susceptible to symptomatic genital HSV-2 infection ${ }^{21}$ as adults. Given the inequality of socioeconomic status across ethnic groups, it is possible that whites may be less exposed to HSV-1 at a young age and were thus more susceptible to symptomatic genital HSV infection as adults. Alternatively, the clustering of viral and bacterial STIs in different ethnic groups may simply reflect sexual mixing patterns. People tend to choose sexual partners within their own ethnic group. $^{22}$

In this study, acquisition of the viral STIs did not appear to be determined by recent high risk sexual behaviour: they were not associated with multiple sex partners and, indeed, females presenting with these infections were less likely to have had an STI previously, compared with all other female attenders. Previous studies have indicated that prevalence of HSV-2 antibody ${ }^{23}$ and a history of genital warts ${ }^{24}$ are associated with the number of lifetime sexual partners, although these studies include long standing infections. By using first episodes only, these analyses focused on risk factors associated with recently acquired infections. Nevertheless, some infections may have been acquired some time before diagnosis.

The bacterial STIs were strongly associated with multiple sex partners and young age. However, data on number of partners were potentially biased as they were dependent on patient recall and because one clinic counted partnerships over a different period. The occurrence of unsafe sexual behaviour, defined as having had two or more sexual partners in the past year without using a condom, has been shown to be far greater in those aged under $25 .{ }^{19}$ Previous studies have shown similar associations between multiple sex partners or partner change, young age, and infection with gonorrhoea $^{25}$ or chlamydia. ${ }^{27} 28$

The perpetuation of an infectious disease within the population requires that the case reproductive rate is greater than unity. For STIs, the reproductive rate is dependent on the rate of partner change and the duration of infectiousness. ${ }^{29}$ Bacterial STIs, because they are more treatable, tend to have a much shorter period of infectiousness than the viral STIs, and thus require higher rates of partner change to be maintained at endemic levels. ${ }^{30} \mathrm{~A}$ high rate of partner change may be less important to maintain endemic levels of viral infections, which are characterised by longer periods of infectiousness. ${ }^{31}$

The results from a study on GUM clinic attenders should be extrapolated to the wider population with caution. However, they suggest that while targeting high risk groups in STI prevention initiatives is appropriate for bacterial STIs, it may have minimal impact on the prevalence of viral STIs. This accords well with modelling work on the transmission dynamics of HSV-2 which suggested that suppressive therapy targeting core groups alone would not result in a decline in HSV-2 prevalence. ${ }^{30}$ Community based studies investigating the underlying causes of high rates of bacterial STIs in certain population subgroups are required to inform targeted control measures. ${ }^{18}$

The project was funded by the Department of Health. We are grateful to Mauri Moreno, Maria Ryder, and Barbara Band for downloading data from the clinic databases and to Ian Simms for commenting on the text

Contributors: $\mathrm{GH}$ and MC conceived the idea of the paper; $\mathrm{GH}$ analysed the data with statistical support from PAR and ARB; GH, MC, ARB, PAR, GK, DM, and NT were involved in interpretation of the results and drafting of the paper; $\mathrm{GH}$ undertook the main writing of the paper.

1 CDSC. Quarterly Communicable Disease Review, July to September 1993. F Public Health Med 1994;16:105-12.

2 CDSC. Sexually transmitted diseases quarterly report: syphilis - national and international epidemiology. Comm Dis Rep CDR Wkly 1999;9:38-9.

3 CDSC. Sexually transmitted diseases quarterly report: genital infection with Chlamydia trachomatis in England and Wales. Comm Dis Rep CDR Wkly 1998;8:390-1.

4 CDSC. Sexually transmitted diseases quarterly report: genital warts and genital herpes simplex virus infection in Eng-

5 Catchpole M. Sexually transmitted diseases in England and Catchpole M. Sexually transmitted diseases in England and

6 Simms I, Hughes G, Swan AV, et al. New cases seen at genitourinary medicine clinics: England 1996. CDR Suppl 1998;8: S1-11.

7 Hughes G, Simms I, Rogers PA, et al. New cases seen at genitourinary medicine clinics: England 1996. CDR Suppl 1998;8:S1-11.

8 Nicoll A, Catchpole M, Cliffe S, et al. Sexual health of teenagers in England and Wales: analysis of national data. BMF 1999;318: 1321-2.

9 Hooykaas C, van der Velde FW, ven der Linden MMD, et al. The importance of ethnicity as a risk factor for STDs and sexual behaviour among heterosexuals. Genitourin Med 1991;67:378-83.

10 Toomey KE, Moran JS, Rafferty MP, et al. Epidemiological considerations of sexually transmitted diseases in underserved populations. Infect Dis Clin N Am 1993;7:739-52.

11 Hughes G, Catchpole M. Surveillance of sexually transmitted infections in England and Wales. Eurosurveillance 1998; ted infecti-5.

12 Catchpole M, Connor N, Brady A, et al. Behavioural and demographic characteristics of attenders at two genitourinary medicine clinics in England. Genitourin Med 1997;73: 457-61.

13 Stata statistical software: Release 5.0 College Station. TX, USA: Stata Corporation, 1997.

14 Low N, Daker-White G, Barlow D, et al. Gonorrhoea in inner London: results of a cross-sectional study. BMF 1997;314:1719-23.

15 Lacey CJN, Merrick DW, Bensley DC, et al. Analysis of the sociodemography of gonorrhoea in Leeds, 1989-93. BMF 1997;314:1715-8.

16 Evans BA, Kell PD, Bond RA, et al. Racial origin, sexual lifestyle, and genital infection among women attending a Transm Infect 1998;74:45-9.

17 Bhopal R. Is research into ethnicity and health racist, unsound or important science? BMF 1997;314:1751

18 Johnson AM, Wadsworth J, Wellings K, et al. Sexual attitudes and lifestyles. Oxford: Blackwell Scientific Publications, 1994

19 Fenton K, Johnson AM, Nicoll A. Race, ethnicity and sexual health. BMF 1997;314:1703.

20 Nahmias A, Roizman B. Infection with herpes simplex viruses 1 and 2. N Engl f Med 1973;289:667-74, 719-25, 781-9.

21 Kinghorn GR. Epidemiology of genital herpes. F Int Med Res 1994;22(suppl 1):14A-23A.

22 Barlow D, Daker-White G, Band B. Assortative sexual mixing in a heterosexual clinic population - a limiting factor in HIV spread? AIDS 1997;11:1041-6. 
23 Cowan FM, Johnson AM, Ashley R, et al. Antibody to herpes simplex virus type 2 as serological marker of sexual life-
style in populations. BMF 1994;309:1325-9.

24 Munk C, Svare EI, Poll P, et al. History of genital warts in 10,838 women 20 to 29 years of age from the general population. Risk factors and association with Papanicolaou smear history. Sex Transm Dis 1997;24:567-72.

25 Bjekic M, Vlajinac H, Sipetic S, et al. Risk factors for gonorrhoea: case-control study. Genitourin Med 1997;73 518-21.

26 Cooper DL, Bernstein GS, Ivler D, et al. Gonorrhoea screening program in a women's hospital outpatient department: results and analysis of risk factors. 7 Am Vener Dis Assoc 1976;3:71-5.

27 Rietmeijer CA, Judson FN, Van Hensbroek MC et al. Unsuspected Chlamydia trachomatis infection in hetero- sexual men attending a sexually transmitted disease clinic: evaluation of risk factors and screening methods. Sex Transm Dis 1991;18:28-35.

28 Smith JR, Murdoch J, Carrington D, et al. Prevalence of Chlamydia trachomatis infection in women having cervical smear tests. BMF 1991;302:82-4.

29 Anderson RM, May RM. Infectious diseases of humans: dynamics and control. Oxford: Oxford University Press, 1991

30 Garnett GP, Anderson RM. Contact tracing and the estimation of sexual mixing patterns: the epidemiology of gonococcal infections. Sex Transm Dis 1993;20:181-91.

31 White PJ, Garnett GP. Use of antiviral treatment and prophylaxis is unlikely to have a major impact on the preva75:49-54. 